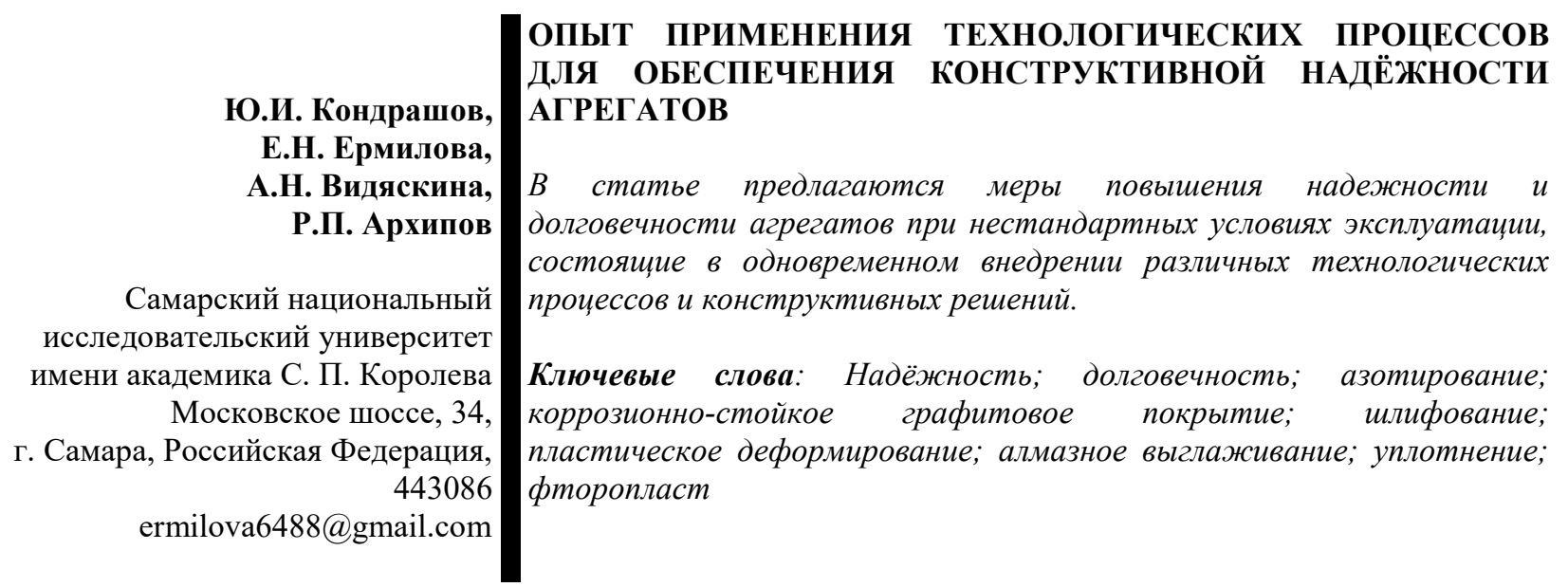

\section{1 Введение}

Научно-технический прогресс в авиационном агрегатостроении должен базироваться на современных методах конструирования и технологических процессах, обеспечивающих создание надёжных, экономичных, высокотехнологичных агрегатов.

Некоторые вопросы, связанные с обеспечением долговечности и надёжности агрегатов при нестандартных условиях эксплуатации, можно зачастую решать путём внедрения различных технологических процессов. Это позволяет расширить диапазон применения материалов деталей агрегатов с минимальными экономическими затратами.

\section{2 Теоретические исследования}

Известно, что для обеспечения работоспособности контактирующих деталей при возвратно-поступательном движении, работающих в условиях сухого трения и высоких температур $+660^{\circ} \mathrm{C}$, необходимо обеспечить контактирующие поверхности деталей твердостью НRC $>56$ при сохранении вязкой сердцевины детали. Это обычно достигается химикотермической обработкой поверхности путём цементации или азотирования. Для сплава $\mathrm{X} 12 \mathrm{H} 22 \mathrm{~T} 3 \mathrm{P}, \quad$ рекомендуемого для применения при таких температурах,

получение такой твёрдости обеспечивает азотирование. На качество азотирования существенно влияет бальность зерна, которая зависит от диаметра заготовки (прутка) детали, режимов термической обработки. По ГОСТ 5639-82 зерна бальности NN 1-5 являются крупными, NN 6-15 относятся к мелким (рисунок 1). Крупнозернистая сталь более склонна к закалочным трещинам, деформации и короблению.

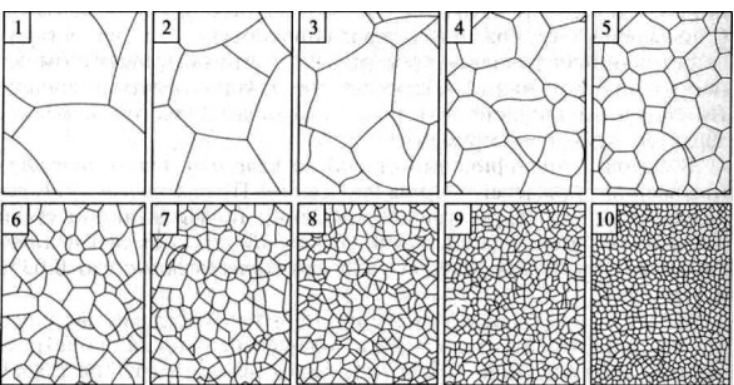

Рисунок 1. Бальность зерна в металлах

При бальности $<5$ (диаметр заготовки $>80$ мм) в процессе эксплуатации с азотируемой поверхности детали происходит выкрашивание по границам зёрен. Таким образом, создаются условия развития коррозионных процессов, а в условиях динамики нагружений и усталостных процессов разрушения. Нанесение поверх азотированного слоя коррозионно-стойкого графитового покрытия решило одновременно две задачи: обеспечение смазки в условиях сухого трения и закрытие 
всех потенциальных очагов возникновения и распространения коррозионных процессов. Графит мелкодисперсной фракции наносился толщиной 10-14 мкм, а затем спекался, образуя защитную пленку. Такая технология защиты деталей (позиции 1,2 на рисунке 2) от воздействия воздушной среды с температурой до $+660^{\circ} \mathrm{C}$ позволила обеспечить длительную эксплуатацию комбинированного регулятора наддува системы кондиционирования самолёта.

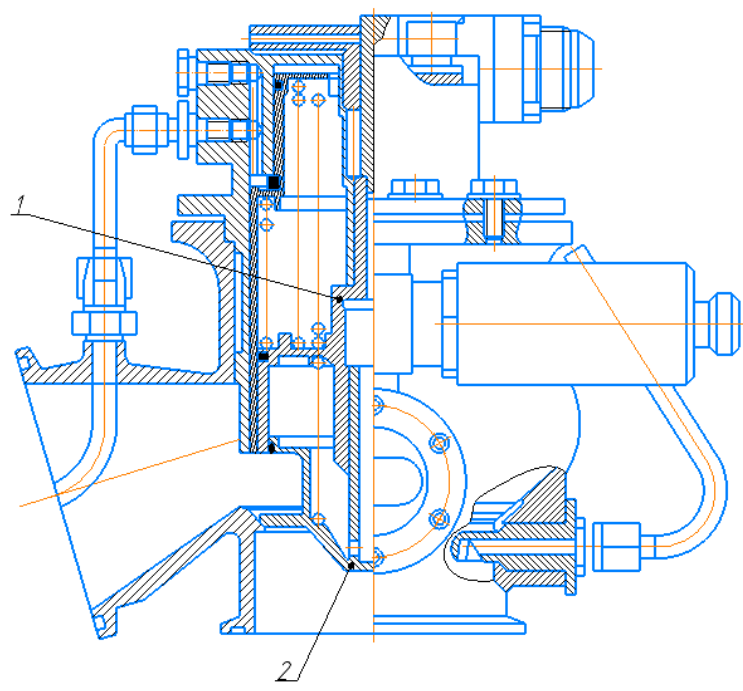

Рисунок 2. Комбинированный регулятор наддува: 1 - поршень; 2 - клапан

Основные технические данные: рабочая среда воздух, температура рабочей среды - до $+660^{\circ} \mathrm{C}$, температура окружающей среды - $\pm 60^{\circ} \mathrm{C}$, расход воздуха - от 600 до 7500 кг/час, давление на "входе" до 1,8 МПа, давление на "выходе" - 0,38...0,45Мпа

Механическая обработка конструкционных материалов в ходе изготовления вносит существенные изменения в строение и свойства поверхностных слоёв. Одна из причин упругая и пластическая деформация. При механическом воздействии интенсивно образуются и перемещаются дислокации, возникают новые структуры, связанные с измельчением и ориентацией зёрен. [3]

Очень важную роль в формировании контактирующих поверхностей агрегатов, влияющих на конструктивную надёжность в условиях длительной эксплуатации агрегатов и при воздействии знакопеременных нагружений, играет алмазное выглаживание. При выглаживании обычно используют одну из рекомендуемых схем (рисунки 3,4 )

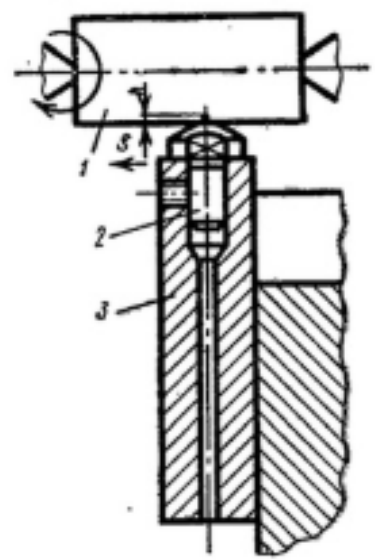

Рисунок 3. Схема жёсткого выглаживания: 1 - валик, 2 - выглаживатель, 3 - державка, S глубина внедрения выглаживания

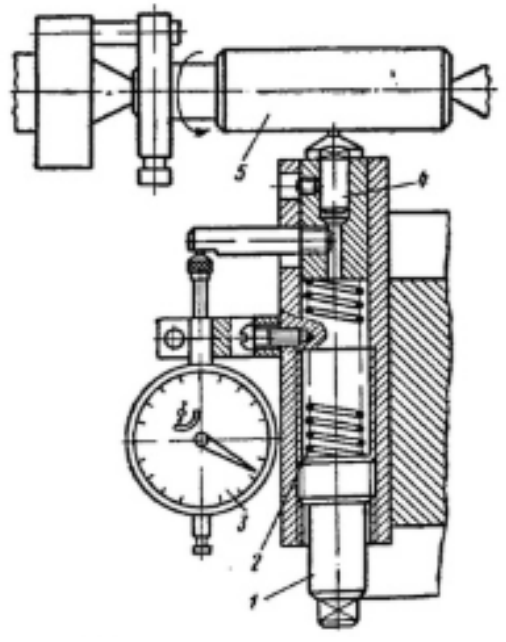

Рисунок 4. Схема выглаживания пружинной державкой:

1 - винт, 2 - тарированная пружина, 3 - индикатор, 4 - выглаживатель, 5 - деталь

Выглаживание с жёстким закреплением выглаживателя может быть рекомендовано для обработки особо точных деталей на станках повышенной точности за одну установку с предшествующей обработкой, либо одновременно с предшествующей обработкой (например, одновременное точение и выглаживание).

Более простой и удобный способ Выглаживание с упругим закреплением инструмента. Для такого способа выглаживания характерно упругое прижатие инструмента к обрабатываемой детали с помощью пружины или другим способом. Сила прижатия выглаживателя к детали, 
зависящая

OT

обрабатываемого

материала

пластичности

шероховатости поверхности, а также радиуса выглаживателя. Эта сила в процессе обработки достаточно легко контролируется и поддерживается постоянной.

Выглаживание является одним из методов отделочно-упрочняющей поверхностным деформированием и пластическом обработки пластическим обрабатываемой поверхности скользящим по ней инструментом - выглаживателем, закреплённым в оправке алмазным кристаллом. При этом неровности поверхности, оставшиеся от предшествующей обработки, сглаживаются частично или полностью, и поверхность приобретает зеркальный блеск, повышается твёрдость поверхностного слоя, в нём создаются сжимающие напряжения. После выглаживания поверхность остаётся чистой, не шаржированной осколками абразивных зёрен, что обычно происходит при процессах абразивной обработки. Сочетание свойств выглаженной поверхности предопределяет её высокие эксплуатационные качества

износостойкость, усталостную прочность и т.Д. [1]

Отличительной особенностью алмазного выглаживания, в сравнении с другими методами обработки поверхностным пластическим деформированием, является применение в качестве деформирующего элемента алмаза, обладающего следующими свойствами: чрезвычайно высокой твёрдостью, низким коэффициентом трения по металлу, высокой степенью чистоты, с которой может быть отполирован алмаз, а также высокой теплопроводностью.

Высокая твёрдость алмаза позволяет обрабатывать практически все металлы, которые поддаюся пластической деформации, как мягкие, так и закалённые до твёрдости HRC 60-65. Малая величина радиуса инструмента-выглаживателя $(0,75-$ 4 мм) обуславливает малую величину силы выглаживания $(5-25$ кгс). Это позволяет обрабатывать тонкостенные и маложёсткие детали и снижает требования к жёсткости технологического оборудования.[1]

Применение выглаживания позволяет уменьшить шероховатость поверхности (отделка), упрочнить поверхностный слой и повысить точность размеров и формы деталей (калибрование).

Выглаженная поверхность отличается от поверхностей, обработанных другими методами. Шлифованная поверхность характеризуется отчётливо различимыми следами резания отдельных зёрен, наплавами размазанного и размягченного металла.

В результате выглаживания образуется более ровная пластически деформированная поверхность, без вырывов и задиров. Профилограммы поверхностей после различных способов обработки представлены на рисунке 5.
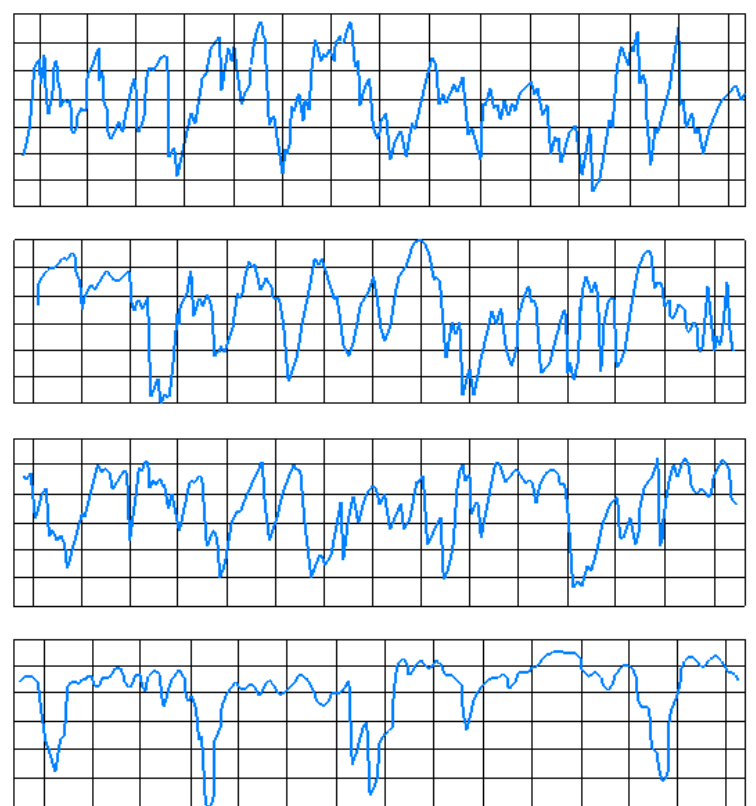

Рисунок 5. Профилограммы поверхностей 10-го класса, обработанных: а - шлифованием, б полированием, в - суперфинишем, г - алмазным выглаживанием (вертикальное увеличение ×100000; горизонтальное увеличение $\times 200$ )

Помимо образования напряжений сжатия в поверхностном слое и уменьшения напряжений растяжения, происходит исправление некруглости обрабатываемых поверхностей до $50 \%$, овальности и конусности до 15-25\% [2,3]. 


\section{3 Результаты исследования}

Применение технологии алмазного выглаживания на деталях позиций 1 и 2 комбинированного регулятора (рисунок 2) в сочетании с вибровыглаживанием и графитизированием контактирующих поверхностей позволило обеспечить функционирование агрегата в пределах назначенного ресурса.

Не менее интересен способ расширения температурного диапазона применения фторопласта-4 в качестве уплотнительного материала в цанговом исполнении уплотнения вала при кратковременном воздействии температуры газа до $+400^{\circ} \mathrm{C}$. На рисунке 6 представлена конструкция газового дросселя.

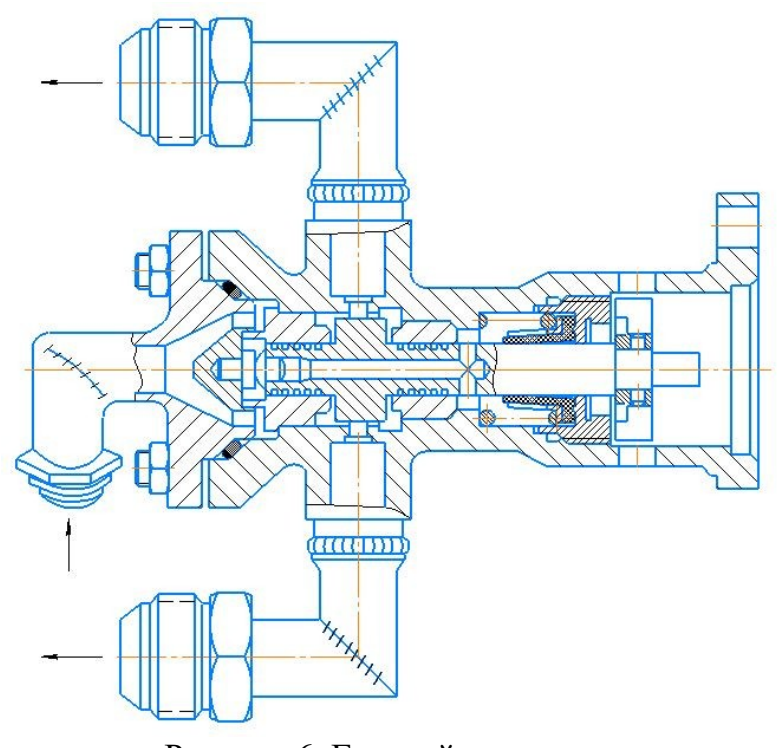

Рисунок 6. Газовый дроссель

Проведёнными исследованиями было установлено, что основное температурное воздействие на уплотнительную кромку фторопластовой манжеты передаётся по уплотняемому валу, поэтому на вал в зоне контакта плазменным способом в вакууме был нанесён рений, обладающий низкой теплопроводностью (рисунок 7), что позволило решить проблему эксплуатации газового дросселя без серьёзных изменений и усложнений конструкции и без изменения габаритных размеров агрегата. Была изменена лишь конструкция уплотнительного элемента (рисунок 7).

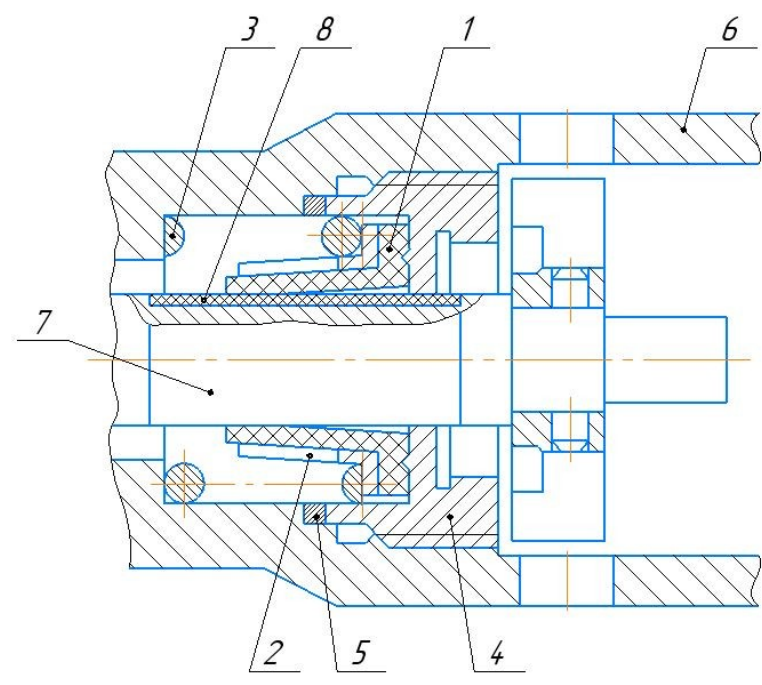

Рисунок 7. Высокотемпературное уплотнительное устройство вращающего вала:

1 - фторопластовая манжета, 2 - разрезная цанга, 3 - пружина, 4 - гайка, 5 - уплотнительное кольцо, 6 корпус, 7 - вращающийся вал, 8 - теплозащитное покрытие

\section{4 Заключение}

Таким образом, взаимодействие конструктивных решений при одновременном использовании возможностей современных технологических процессов по улучшению состояния контактирующих поверхностей агрегатов позволяет существенно расширить температурный диапазон применения агрегатов при обеспечении заданной конструктивной надёжности.

\section{5 Благодарности}

Результаты исследования были получены в рамках выполнения государственного задания Минобрнауки России (Проект № 9.1517.2017/ПЧ).

\section{Список использованных источников}

[1] Кондрашов, Ю. И. Конструкция и проектирование агрегатов и систем [Электронный ресурс]: электрон. учеб. Пособие / Ю. И. Кондрашов // Минобрнауки России, Самар. гос. аэрокосм. ун-т им. С. П. Королева (нац. исслед. ун-т). - Электрон. 
текстовые и граф. дан. (39,8 Мбайт). - Самара, 2011. 1 эл. опт. диск (CD-ROM).

[2] Демкин Н. Б. Качество поверхности и качество деталей машин / Н. Б Демкин, Э. В. Рыжов. - М.: Машиностроение, 1981. - 244 с.

[3] Браун Э. Д. Основы трибологии: (Трение, износ, смазка): Учеб. для техн. вузов / Э. Д. Браун, Н. А. Буше, И. А. Буяновский и др.; под ред. А. В. Чичинадзе. - М.: Центр «Наука и техника», 1995. 777
[4] Основы создания агрегатов автоматики пневмогидравлических систем летательных аппаратов и двигателей. Часть 1. Обеспечение конструкторской надежности и технологичности агрегатов / А. Н. Евстигнеев, А. Е. Жуковский, В.М. Ивасов, Ю.И.Кондрашов и др. - Самара: НПО "Импульс", 1993. - 375 с.

[5] Одинцов Л. Г. Финишная обработка деталей алмазным выглаживанием и вибровыглаживанием / Л. Г. Одинцов. - М.: Машиностроение, 1981. - 160 с. 


\begin{tabular}{|c|c|}
\hline $\begin{array}{l}\text { Yuriy I. Kondrashov, } \\
\text { Anna N. Vidyaskina, } \\
\text { Elena N. Ermilova, } \\
\text { Ruslan P. Arkhipov, }\end{array}$ & $\begin{array}{l}\text { EXPERIENCE OF APPLICATION OF TECHNOLOGICAL } \\
\text { PROCESSES FOR ENSURING THE CONSTRUCTIVE } \\
\text { RELIABILITY OF UNITS } \\
\text { The article proposes measures to improve the reliability and durability o } \\
\text { f the units under non- } \\
\text { standard operating conditions, consisting in the simultaneous introducti } \\
\text { on of various technological processes and design solutions. }\end{array}$ \\
\hline $\begin{array}{r}\text { Samara National Research University } \\
\text { Moskovskoe shosse, 34,Samara, 443086, } \\
\text { Russian Federation } \\
\text { ermilova6488@gmail.com }\end{array}$ & $\begin{array}{l}\text { Key words: Reliability; } \\
\text { corrosionresistant graphite coating; } \\
\text { diamond smoothing; sealing; fluoroplastic }\end{array}$ \\
\hline
\end{tabular}

\section{References}

[1] Kondrashov, YU. I. (2011), "Konstruktsiya i proektirovanie agregatov i sistem" [Construction and design of units and systems] [Electronic source]: electronic learning guide, Minobrnauki Rossii, Samara State Aerospace University n.a. S. P. Korolev (national research university), Electronic text and graphic data. (39,8 Mbajt), Samara,. - 1 el. opt. disk (CD-ROM).

[2] Demkin, N.B. and Ryzhov, E.V. (1981), Kachestvo poverhnosti i kachestvo detalej mashin [Surface quality and quality of machine parts], Mashinostroenie, Moscow, Russia, 244 p.

[3] Braun E. D., Bushe N. A., Buyanovskij I. A. et. al. (1995), Osnovy tribologii (trenie, iznos, smazka) [ The basics of tribology (friction, wear, lubrication)], in CHichinadze, A.V. (ed.), Nauka i tekhnika, Moscow, Russia, 777 p.

[4] Evstigneev, A.N., ZHukovskiy, A.E., Ivasov, V.M., Kondrashov, YU.I. et al. (1993), Osnovy sozdaniya agregatov avtomatiki pnevmogidravlicheskih sistem letatel'nyh apparatov i dvigatelej [Basics of creating automation units for pneumatic-hydraulic systems of aircraft and engines.]. Part 1. Obespechenie konstruktorskoj nadezhnosti i tekhnologichnosti agregatov [Ensuring design reliability and manufacturability of units], NPO "Impul's", Samara, Russia, $375 \mathrm{p}$.

[5] Odincov, L.G. (1981), Finishnaya obrabotka detalej almaznym vyglazhivaniem i Vibrovyglazhivaniem [Finishing of details by diamond smoothing and vibration smoothing], Mashinostroenie, Moscow, Russia, 160 p. 